\title{
Social networks and contraceptive dynamics in southern Ghana
}

\author{
Mark R. Montgomery \\ Population Council \\ Gebre-Egziabher Kiros \\ Population Council \\ Dominic K. Agyeman \\ John B. Casterline \\ Population Council \\ Peter Aglobitse
}

See next page for additional authors

Follow this and additional works at: https://knowledgecommons.popcouncil.org/departments_sbsr-pgy

Part of the Demography, Population, and Ecology Commons, Family, Life Course, and Society Commons, and the International Public Health Commons How does access to this work benefit you? Let us know!

\section{Recommended Citation}

Montgomery, Mark R., Gebre-Egziabher Kiros, Dominic K. Agyeman, John B. Casterline, Peter Aglobitse, and Paul C. Hewett. 2001. "Social networks and contraceptive dynamics in southern Ghana," Policy Research Division Working Paper no. 153. New York: Population Council. 


\section{Authors}

Mark R. Montgomery, Gebre-Egziabher Kiros, Dominic K. Agyeman, John B. Casterline, Peter Aglobitse, and Paul C. Hewett 


\section{Social Networks and Contraceptive Dynamics in Southern Ghana}

Mark R. Montgomery

Gebre-Egziabher Kiros

Dominic Agyeman

John B. Casterline

Peter Aglobitse

Paul C. Hewett 


\title{
Social Networks and Contraceptive Dynamics in Southern Ghana
}

\author{
Mark R. Montgomery \\ Gebre-Egziabher Kiros \\ Dominic Agyeman \\ John B. Casterline \\ Peter Aglobitse \\ Paul C. Hewett
}

John B. Casterline and Mark R. Montgomery are Senior Associates, Policy Research Division, Population Council, New York. Gebre-Egziabher Kiros is a Berelson Fellow in the Policy Research Division, Population Council, New York. Dominic Agyeman and Peter Aglobitse are on the faculty of the University of Cape Coast, Ghana. Paul C. Hewett is Research Associate, Policy Research Division, Population Council, New York. 


\begin{abstract}
There is accumulating evidence that social diffusion processes affect the pace of the adoption of modern contraception in societies undergoing fertility transition. In settings where mortality has declined and many other social and economic changes are underway, decisions about contraception are fraught with uncertainty and risk. In such circumstances, couples may rely on other persons for information and guidance. In this paper, we examine the influence of informal social networks on the contraceptive behavior of reproductive-age women, using longitudinal data collected in six communities in southern Ghana. Our results confirm the hypothesis that adoption of modern contraception is strongly affected by the reproductive attitudes and behaviors of social network partners. What might be termed "social contagion" accelerates the adoption of contraception. Finally, our data reveal that social networks are structured along the lines of social, economic, and cultural characteristics, suggesting further pathways by which socioeconomic variables can influence reproductive behavior.
\end{abstract}

This material may not be reproduced without written permission from the authors. 
Most contemporary theories of the fertility transition reserve a place for social diffusion effects (Bongaarts and Watkins 1996; Mason 1997; Casterline 2001). These effects arise because individuals are members of social groups and routinely encounter the attitudes and behaviors of other persons. The information that is held by other persons, the choices those persons make, and the outcomes that flow from them can all exert an influence on individuals' evaluations of the advantages and disadvantages of various reproductive behaviors. This influence is likely to be especially powerful when the behavior is innovative and hence presents risks and promises benefits that are not yet well understood. This characterization applies to the use of modern contraceptive methods in settings such as West Africa, where fertility has been high and practice of modern contraception rare. In such settings, information that individuals acquire through social interaction may have a critical bearing on their reproductive decisionmaking. The connections among individuals_-social networks_-become the pathways along which innovative demographic attitudes and behaviors can diffuse.

This is a familiar notion in the literature on fertility transition, first coming to prominence in research on the decline of fertility in Europe (Knodel and van de Walle 1979; Watkins 1990). In this earlier literature, diffusion is invoked ex post in an effort to account for features of the decline that scholars found puzzling and difficult to place within existing conceptual frameworks. In this older literature, "diffusion" and "diffusion effects" are not precisely defined, nor are they embedded in well-articulated behavioral models. As a result, one has difficulty ascertaining what empirical tests would determine whether diffusion effects exist (and estimate their magnitude) and what types of data would be required to carry out such tests. During the past decade, however, substantial progress has been made in correcting these deficiencies. The diffusion argument has been pursued more rigorously and systematically, beginning with clearer statements of the underlying behavioral models (Kohler 2001; Palloni 2001).

In our own efforts to specify the diffusion argument (Montgomery and Casterline 1993, 1996, 1998; Casterline 2001), we have defined diffusion effects as the effects of the knowledge, attitudes, and behaviors of other persons on an individual's likelihood of making certain choices. We have proposed that such effects are the outcome of two fundamental processes: social learning and social influence. Social learning refers to 
the acquisition of information through contact with other persons, with information defined broadly to include everything from technical knowledge to behavioral norms. Social learning is a pervasive feature of social experience but is especially salient in environments characterized by flux and uncertainty, in which new options are coming to the fore but with associated costs and benefits that are not yet well understood. In such transitional settings, individuals may seek to understand the consequences of a new private decision, and may probe in various directions hoping to clarify the nature of its potential benefits and costs. Other persons_-perhaps an intimate friend or kin relation, perhaps a workplace associate, or perhaps a health provider-may be the source of information that tips the balance in favor of one decision as against another. This is a capsule description of a complex behavioral and cognitive process that encompasses both the social aspects of information acquisition and the filtering or distillation of that information into terms that are meaningful to individual choice (Carley 2001).

Social influence is a rather different concept, referring to the constraints on decisions that derive from structures of authority and from socially conditioned deference. Such constraints exist in all societies, reflecting asymmetries in power derived from economic wealth, political position, kinship relationship, and so forth. Social normscollectively held understandings about which behaviors are acceptable and unacceptable - are one prominent mechanism for maintaining the constraints associated with social influence. As individuals consider innovative choices, they may find that various groups, institutions, or local elites are positioned either to facilitate or to constrain the adoption of those choices. But such social structures are themselves rarely immutable or impervious to influence. Indeed, in a type of feedback process, the constraints on innovative behavior may well change in tandem with the prevalence of an innovation. For instance, social norms favoring high fertility may dissolve or be reconfigured as modern contraceptive use spreads.

The discussion so far has implied that social learning and social influence operate through face-to-face social interaction. But these mechanisms can also act at a distance, when knowledge is gleaned from the media, for example. Such sources of social learning and social influence can be labeled impersonal. The distinction between inter- 
personal and impersonal sources should not be drawn too sharply. Information obtained from the media is often passed on and evaluated through further social interaction (Hornik and McAnany 2001). Contacts with family planning programs often have both an interpersonal and an impersonal character.

Social learning and social influence are the behavioral mechanisms that account for diffusion, as we have defined this concept. These mechanisms are intuitively plausible, and they are consistent with major bodies of theory and empirical research in sociology and economics. While it is far from straightforward to measure either mechanism directly, together they provide a sound rationale for examining the effects of social interaction on various reproductive behaviors.

Our main interest in the present analysis of data from Ghana is contraceptive behavior. We have every reason to expect that in this setting use of modern contraception may be strongly influenced by social diffusion effects. One aspect of social learning has to do with the properties of contraceptive methods themselves - their levels of efficacy, where they may be obtained, the associated monetary and social costs, and the potential side effects of use. These are doubtless central concerns in settings such as Ghana, where contraceptive prevalence is low (nationwide, 22 percent in 1998; in the Central Region where this study is located, 19 percent in 1998; see Ghana Statistical Service and Macro International 1999). But the scope for social learning goes far beyond information about contraceptive methods per se. Widespread economic, cultural, and social changes are underway in Ghana, themselves resulting in substantial demographic changes (e.g., improvements in child survival). Social learning is one mechanism through which Ghanaians draw conclusions about the meaning of these larger processes. A key issue, for example, may be the risks and benefits of heavy investments in children's schooling, an issue that has been heightened by recent increases in schooling fees in Ghana. Assessments of the returns to schooling, in turn, are affected by expectations of changes in the economy, perceptions of diminishing loyalty to filial obligations, and so forth. Learning in these areas involves factors distinct from the properties of contraceptive methods, but such learning could ultimately be expressed through contraceptive use. 
One should not presume that social learning and social influence must reinforce innovation. The impression from research in developing countries is that conversation about modern contraception is far more often negative than positive, with stories about extreme negative health repercussions of contraceptives often dominating the discussion (for Senegal, see Ngom 1995; for Kenya, see Rutenberg and Watkins 1997). Similar health concerns are widespread in Ghana, as documented by Adibo (1992), Adongo et al. (1997), and Agyeman et al. (1996). Health scares, backlashes, the disapproval of local elites, the public failure of innovators-all these social effects frustrate rather than encourage innovation. This makes a more fundamental point, namely that trends in contraceptive use do not in themselves shed light on the nature of the information that has been exchanged. Offsetting positive and negative messages about contraception may be exchanged, so that the net change in the prevalence of use is not necessarily indicative of the salience of the information communicated. Moreover, as we have already suggested, contraceptive use may serve only as a signal of the diffusion of more fundamental messages on the motivations for childrearing, and these messages need not have any direct connection to the properties of contraceptive methods themselves.

Our aim in this paper is to conduct an empirical test of some of the notions sketched in the preceding paragraphs. The argument for the existence of diffusion effects on the timing and pace of fertility decline is plausible, even compelling. But what empirical evidence supports this argument? Elsewhere we have reviewed the research literature (Montgomery and Casterline 1998; see also Cleland 2001; Palloni 2001). While proponents can find numerous hints and indirect suggestions of a role for diffusion in the empirical record, in our view much of the evidence does not withstand rigorous scrutiny. What the diffusion argument requires, at a minimum, is some linkage between social interaction patterns, broadly defined, and reproductive behavior. To date only few rigorous efforts have been made to examine such linkages (Entwisle et al. 1996; Valente et al. 1997; Montgomery and Chung 1999; Kohler 2001; Kohler et al. 2001). In this paper we present results from ongoing longitudinal research in southern Ghana in which reproductive behavior and patterns of social interaction are both measured in detail at the individual level over time, thereby offering an opportunity to test for diffusion effects on reproductive behavior. 


\section{DATA}

The data for this analysis are drawn from the first four rounds of an ongoing multi-round household survey conducted in southern Ghana. The data collection, which began in late 1998 and is slated to continue into 2002, is based at the University of Cape Coast. ${ }^{1}$ The sample universe is women aged 18 through 50 at the time of the baseline interview in 1998, irrespective of marital status, along with the male partners of those women in formal unions, residing in six communities. These six communities, which are isolated from each other, were purposively selected to provide diversity of ecological setting, economic activity, ethnicity, and kinship system.

Their diversity is summarized in Table 1. In terms of ecological setting and economic activity, a deliberate effort was made to maximize between-community differences, and this was achieved to a greater extent than is apparent from the characteriza-

Table 1 Basic features of the six study communities in southern Ghana

\begin{tabular}{|c|c|c|c|c|c|c|}
\hline & Abuesi & Amanfro & Brenu & Frami & Komfoeku & Tubaman \\
\hline Ecology & Coastal & Inland & Coastal & Inland & Inland & Inland \\
\hline $\begin{array}{l}\text { Primary economic } \\
\text { activity }\end{array}$ & Fishing & Trading & $\begin{array}{l}\text { Farming, } \\
\text { fishing }\end{array}$ & Farming & Farming & Farming \\
\hline $\begin{array}{l}\text { Mean number of } \\
\text { household possessions a }\end{array}$ & 3.5 & 4.6 & 3.4 & 2.7 & 3.2 & 5.0 \\
\hline $\begin{array}{l}\text { Percent of households } \\
\text { electrified }{ }^{\text {a }}\end{array}$ & 88 & 85 & 71 & 79 & 74 & 82 \\
\hline \multicolumn{7}{|l|}{$\begin{array}{l}\text { Percent having middle } \\
\text { schooling or higher }^{b}\end{array}$} \\
\hline Women & 27 & 45 & 58 & 49 & 30 & 32 \\
\hline Men & 32 & 79 & 60 & 77 & 62 & 41 \\
\hline \multicolumn{7}{|l|}{ Religious affiliation $^{c}$} \\
\hline Orthodox Christian & 29 & 17 & 71 & 50 & 38 & 4 \\
\hline Pentecostal Christian & 37 & 68 & 19 & 41 & 46 & 6 \\
\hline Muslim & 24 & 7 & 2 & 0 & 0 & 90 \\
\hline $\begin{array}{l}\text { Primary ethno-linguistic } \\
\text { group }\end{array}$ & Fante & $\begin{array}{c}\text { Ga- } \\
\text { Adangbe }\end{array}$ & Fante & Denkyira & Fante & $\begin{array}{c}\text { Ga- } \\
\text { Adangbe }\end{array}$ \\
\hline
\end{tabular}

a Calculated for reproductive-age women interviewed in round 3 of panel survey. Adjusted for community differences in age and marital status (through Poisson and logit regressions). Household possessions include main source of water, type of toilet, electricity, radio, television, bicycle, hand truck, refrigerator, and sofa or chair. b Calculated for reproductive-age women and their male partners interviewed in round 1 of panel survey. Adjusted for community differences in age and, for women, marital status (through logit regression).

c Percent distribution of reproductive-age women interviewed in round 1 of panel survey. 
tions in Table 1. Comparing the farming communities, for example, Frami and Komfoeku are situated in low-lying hills and the farming is largely of a subsistence variety, whereas Brenu and Tubaman, both located on the coastal plain, devote more effort to cash crops. Roughly the same percentage of households is electrified in the six communities, ranging from 71 percent in Brenu to 88 percent in Abuesi. The mean number of household possessions, intended as a proxy for household wealth, shows more between-community variation, with a low of 2.7 in Frami and a high of 5.0 in Tubaman. Adult school attainment is highest in Amanfro and Frami, and lowest in Abuesi and Tubaman. Amanfro-a peri-urban market town less than an hour's drive from the national capital of Accra-clearly is more advantaged according to the socioeconomic indicators, but otherwise the communities that are high or low according to the different indicators vary in an inconsistent pattern.

The sample communities are heterogeneous in their religious affiliation (next-tolast panel of Table 1). Tubaman is largely Muslim and Abuesi is about one-quarter Muslim. The progression of Islam into West Africa for the most part stopped short of the coast (Islam of course is the dominant religion in many parts of interior West Africa), but there are nevertheless significant Muslim communities along the coast. Four ethnic groups are substantially represented in the sample-Fante (roughly half the sample, as expected since this is the dominant ethnic group in this part of Ghana), Denkyira, Ga, and Adangbe, with two other groups also distinguishable (Ewe and Ahanta, found mainly in Amanfro). Three of the communities are relatively homogenous in their ethnic composition-Abuesi, Brenu, and Tubaman - whereas the others possess some diversity, Amanfro in particular. The primary lineage type follows from the ethnic composition, with the four communities dominated by Akan-speaking groups (Fante and Denkyira) being matrilineal and the other two communities patrilineal. This is, of course, a crude characterization of kinship rules that are both subtle and complex. Various marriage and coresidence arrangements can be regarded as consistent with the overarching kinship rules.

Five rounds of the panel survey have been completed, and a sixth is in the field. This analysis uses data collected in the first four rounds. The dates of the fieldwork for rounds 1-4 were as follows: October 1998-February 1999; May 1999-August 1999; February-May 2000; and September-December 2000. Sample retention from the first 
through the fourth rounds (roughly two elapsed years), 92 percent among women, is a solid achievement in any setting and exceptional in West Africa, where rates of residential and circular mobility are high. Success in sample retention varies among the six study communities, ranging from a low of 87 percent in Abuesi to a high of 96 percent in Tubaman. In total, 1,280 women were interviewed in round 1, of whom 983 were in a sexual partnership (henceforth "married") at the time. ${ }^{2}$ A small number of additional women were added to the sample in round 2 (in-migrants to the communities), but the present analysis is limited to married women interviewed in all four rounds.

The behavior that we analyze here is the practice of modern contraception. In the round 1 interview, women were asked in detail about their contraceptive use at the time. In rounds $2-4$, women were reminded of their reported contraceptive status at the previous interview and were then asked about their contraceptive practice from the previous interview to the current interview on a month-by-month basis. The monthly contraceptive calendar included further items about the experience of side effects during months of use and about whether advice was received from a family planning or health worker. Monthly calendars for the inter-round period were also completed for pregnancy status and postpartum behavior (abstinence and breastfeeding) as well as for marital status. Because contraceptive use is the dependent variable in this analysis, we exclude months when the woman was pregnant (including the month of termination of the pregnancy, whether resulting in a live birth or other reproductive outcome) or not in union. These exclusions reduce the sample to 881 women, contributing a mean of 19.2 and a median of 21 observational months, with 60 percent of the women providing information for 17-24 months. The resulting number of observations (woman-months) is 15,024.

As we indicated earlier, our main objective is to consider the effects of social interaction on reproductive behavior, specifically modern contraceptive use. The investigation of social interaction effects-defined broadly to include informal personal networks, contact with others through schooling and employment, participation in voluntary organizations, and mass media exposure-has been the principal motivation for the data collection based at the University of Cape Coast; hence on these topics the survey instruments contain large blocks of items not ordinarily found in demographic survey questionnaires. For the purposes of modeling behavior in the period between rounds 1 
and 4, we restrict ourselves to measurement of social interaction in rounds 1 and 2 . The pertinent items fall into four categories.

Mass media exposure. Women were asked about their frequency of reading newspapers and magazines, listening to the radio, and watching television.

Geographic mobility. With reference to the year preceding the survey, women were asked whether their work took them to other villages or towns, and, irrespective of employment, how often they had visited other communities (Accra; other large cities; towns; rural areas).

Contact with health and family planning workers. With reference to the period between the two rounds of the survey, women were asked: "Did you receive advice from, or have a discussion with, a health or family planning worker?" Those women who answered "yes" were asked to identify the specific month(s) in which the contact occurred and to describe the content of the advice or discussion.

Social networks. The respondents were asked about two types of social networks. These are conversational networks, defined in terms of the discussion of certain topics. The first type might be regarded as general social networks. In round 1, the women were asked the following:

We all talk to others about important matters in our lives. I would like to ask about the people other than your husband/partner whose opinions are important to you. They are people with whom you discuss your personal affairs or private concerns, such as children's illness, schooling, pregnancy, work, and church. They can live nearby or far away, and you might talk to them frequently or infrequently. Other than your husband/partner, can you please give me the names of people whose opinions matter to you?

The second type is networks defined by conversation about modern contraception. In round 2 , the women were asked:

I would like to ask you about the people other than your husband/partner with whom you discuss modern contraception. These are people with whom you have discussed the costs and benefits of modern contraceptive meth- 
ods, where they can be obtained, their side effects, and how the methods are used. These people can live nearby or far away, and you might talk to them frequently or infrequently. Other than your husband/partner, can you please give me the names of people with whom you have discussed modern contraception in the last 12 months?

In both rounds, the interviewer was instructed to record all the names that the respondent volunteered. Among the married women selected for this analysis, the mean number of network partners named is 3.5 in round 1 (general social networks) and 1.6 in round 2 (modern contraception network). Extensive information was then obtained about each of the first four persons named (or fewer, if fewer than four were named): their demographic and socioeconomic characteristics; place of residence and frequency of interaction with the respondent; nature of the relationship between the respondent and the network partner (e.g., whether the network partner is a "confidant"); and, of special value for this analysis, a set of items about fertility and contraception. In round 1, the respondent was asked whether she had discussed childbearing matters with the network partner, whether she felt the network partner approved of modern contraception, and whether she believed the network partner had ever used modern contraception (with a probe into the basis for this belief). In round 2, the respondent was asked whether she felt the network partner approved of modern contraception, whether she believed the network partner had ever used modern contraception (with a probe into the basis for this belief), which method she believes the network partner has used, and questions about whether the respondent and network partner had ever encouraged or discouraged each other from using modern contraception.

Note that the name-generator for the round 1 social network does not refer specifically to contraceptive practice, although it does refer incidentally to reproductive behavior. Only after an individual was named as someone "whose opinions are important to you" was the respondent asked the questions concerning reproductive behavior, including the two questions about modern contraception. This sequence is important for our analysis because our aim is to model contraceptive practice as a function of the respondent's exposure to the contraceptive attitudes and behaviors of other persons. To 
the extent the empirical measures of that exposure are themselves affected by the contraceptive attitudes and behaviors of the respondent, the estimates of causal effects of social exposure on contraception are biased. By measuring the respondents' perceptions of the contraceptive attitudes and behaviors of social network partners who were identified by non-reproductive criteria, we reduce the likelihood of such bias. It remains a possibility, however, that the respondent's perceptions of her network partners' attitudes and behaviors related to childbearing and modern contraception have been influenced by the respondent's own motivation to use contraception and/or past contraceptive practice. This possibility is far greater for the round 2 network data, since the name-generator in round 2 is discussion of modern contraception. We return to this issue below when discussing analytical approaches that we adopt in a further effort, beyond the measurement strategy just discussed, to avoid this source of bias in our estimates of diffusion effects.

The variables for mass media and geographical mobility contain no explicit reference to exposure to reproductive attitudes and behaviors. In examining effects of these variables on contraception, our underlying assumption is that exposure to the mass media and visits to other localities present women with distinctive information-about the costs and benefits of childbearing, or more specifically about contraception and the attributes of specific methods-that they might not otherwise encounter and that could modify their assessment of the desirability and feasibility of using contraception. This information may be derived from direct observation of other women or be gleaned indirectly from advertisements, soap operas, and news.

The Cape Coast surveys also contain measurement of a large number of other likely determinants of contraceptive practice. These variables, shown in Table 2, serve as controls in the analysis. They are, for the most part, conventional in their definition and measurement, and hence are not discussed at length here. They include indicators of exposure and fecundability, motivation to practice contraception, schooling of the respondent and her husband, and an index of household possessions. Between-community differences are also accounted for through a set of dummy variables in the regression models. 


\section{DESCRIPTIVE FINDINGS}

We begin by reviewing the differentials in use of a modern contraceptive method according to the control variables (see Table 2). To repeat, the unit of observation in this analysis is woman-months of exposure to contraceptive use. The observation time is the period from round 1 to round 4, with 881 women contributing 15,024 months during which they are in union and not pregnant.

\section{Exposure, fecundability, fertility preferences, and health}

Beginning with the exposure and fecundability indicators, contraceptive use varies little by age, consistent with the West African pattern, which is distinctive in comparison to other regions: see Bledsoe et al. (1994, 1998) and Caldwell et al. (1992). Use is lower among women who report that they have difficulty conceiving and during months when women report that they are observing postpartum abstinence; it is also lower in months when the husband is reported to have been away for half the month or more. Among the indicators of motivation, use of a modern method is more likely among women who want to space births or terminate childbearing and whose husband (according to the wife's perception) wants to space births or does not want another birth.

Contraceptive use is also higher among women who, during the round 2 interview, report having had no health problems during the past year or who regard themselves as healthier than other women in their community. These health-related differentials require some interpretation. Bledsoe et al. $(1994,1998)$ describe how women in the Gambia use modern contraception to postpone the next pregnancy in the interest of protecting their health, a practice that should result in less contraceptive use among women who perceive themselves to be relatively healthy. It is also common for women to perceive modern contraceptive methods (especially hormonal methods and the IUD) as stressful to health (Nag 1984; Bongaarts and Bruce 1995; Yinger 1998; Casterline and Sinding 2000). Both of these perceptions would produce a negative association between perceived health status and contraception, contrary to the pattern apparent in Table 2. It is not difficult, however, to explain how similar logic might produce the positive association in Table 2. Women may feel that contraceptive use protects their 
Table 2 Distribution of the sample and percent using a modern method of contraception, according to explanatory variables

\begin{tabular}{lcc}
\hline Explanatory variable and category & $\begin{array}{c}\text { Distribution of sample } \\
(\mathbf{n}=\mathbf{1 5 , 0 2 4} \text { woman-months })\end{array}$ & $\begin{array}{c}\text { Percent using modern } \\
\text { contraception }\end{array}$ \\
\hline Total & 100.0 & 20.5
\end{tabular}

Exposure, fecundity, fertility preferences, and health

Age

$<25$

25-29

$30-34$

35-39

$40-44$

$>44$

Perceived fecundability

Becomes pregnant easily

Difficulty conceiving

Postpartum abstinence

Not abstaining

Abstaining

Husband's absence

Not away more than half of current month

Away more than half of current month

Woman's desire for more children

Wants more soon

Wants more later

Wants no more

Husband's desire for more children

Wants more soon

Wants more later

Wants no more

Health problems recently

None

Mild

Severe

Social and economic variables

Woman's schooling

None

37.4

24.6

38.0

Primary

Middle school or higher
21.9

20.6

20.9

27.0

11.3

18.0

50.4

25.8

49.6

15.2

85.1

23.4

14.9

81.7

21.4

18.3

16.5

23.6

33.7

9.5

25.1

23.0

40.7

13.2

27.2

31.6

24.2

61.1

24.6

19.6

17.7

19.3
16.4

20.3

24.8 
Table 2 (continued)

\begin{tabular}{|c|c|c|}
\hline Explanatory variable and category & $\begin{array}{c}\text { Distribution of sample } \\
(\mathbf{n}=\mathbf{1 5 , 0 2 4} \text { woman-months })\end{array}$ & $\begin{array}{c}\text { Percent using modern } \\
\text { contraception }\end{array}$ \\
\hline \multicolumn{3}{|l|}{ Husband's schooling } \\
\hline None & 38.1 & 16.6 \\
\hline Primary & 3.0 & 29.4 \\
\hline Middle school & 43.6 & 22.3 \\
\hline Secondary or higher & 15.3 & 23.7 \\
\hline \multicolumn{3}{|l|}{ Household economic index (quartile) ${ }^{\mathrm{a}}$} \\
\hline First & 18.2 & 20.5 \\
\hline Second & 26.4 & 18.5 \\
\hline Third & 29.6 & 19.5 \\
\hline Fourth & 25.9 & 23.8 \\
\hline \multicolumn{3}{|l|}{$\begin{array}{l}\text { Mass media, urban experience, } \\
\text { and program contact }\end{array}$} \\
\hline \multicolumn{3}{|l|}{ Reads newspaper/magazine } \\
\hline No & 85.5 & 20.1 \\
\hline Yes & 14.5 & 22.8 \\
\hline \multicolumn{3}{|l|}{ Listens to radio at least once a week } \\
\hline No & 40.0 & 16.6 \\
\hline Yes & 60.0 & 23.2 \\
\hline \multicolumn{3}{|l|}{ Recently visited Accra } \\
\hline No & 58.1 & 18.2 \\
\hline Yes & 41.9 & 23.8 \\
\hline \multicolumn{3}{|l|}{ Recently visited other cities } \\
\hline No & 45.0 & 19.0 \\
\hline Yes & 55.0 & 21.8 \\
\hline \multicolumn{3}{|c|}{$\begin{array}{l}\text { Received contraceptive advice at least once } \\
\text { from health or family planning worker, } \\
\text { round } 1 \text { through previous month }\end{array}$} \\
\hline No & 80.2 & 15.5 \\
\hline Yes & 19.8 & 40.7 \\
\hline \multicolumn{3}{|l|}{ Community } \\
\hline Abuesi & 18.2 & 13.4 \\
\hline Amanfro & 13.1 & 22.8 \\
\hline Brenu & 13.9 & 18.6 \\
\hline Frami & 19.2 & 34.5 \\
\hline Komfoeku & 18.8 & 11.6 \\
\hline Tubaman & 16.9 & 22.2 \\
\hline
\end{tabular}

a Constructed on the basis of an inventory of household possessions described in Table 1, using factor analysis. 
health; indeed this may be a primary motivation for using contraception. Hence the pattern in Table 2 might reflect the fact that women who use contraception have positive perceptions of their health, and/or that contraceptive practice leads to an improvement in women's perceptions of their health.

\section{Social and economic variables}

As is the case in most settings, use is positively associated with schooling (of the woman and her husband), although the differentials here are perhaps smaller than expected. Both the woman's and her husband's schooling are moderately associated with the likelihood of contraceptive use. Contraception varies little according to a count of household possessions (as ascertained in round 3), a measure intended to reflect household wealth (Montgomery et al. 2000).

\section{Mass media, urban experience, and program contact}

More closely tied to the main objectives of this research are the variables in Table 2 that refer to mass media exposure and geographical mobility. A small minority of women report that they read newspapers or magazines, and these women are only slightly more likely to be using contraception than the large majority who do not read print media. Somewhat stronger is the relationship between listening to the radio and using contraception (a 6 percentage point difference). With respect to geographical mobility, women who have visited Accra or other cities are more likely to use contraception; the differentials are smaller than those for listening to the radio and the schooling variables. We reiterate that the mass media and geographical mobility variables do not refer directly to exposure to reproductive attitudes and behaviors. Even so, we had hypothesized that wider exposure to the mass media and greater geographical mobility (especially to and from urban areas) would lead to more exposure to attitudes and behaviors favorable to practice of modern contraception, hence would be associated with a greater likelihood of contraceptive practice. These hypotheses gain only weak support in the evidence presented in Table 2. We nevertheless retain these variables for the regression analysis.

Women were asked on a month-by-month basis about their receipt of advice from, or discussion with, health and family planning workers about contraception. After ex- 
perimenting with different specifications, we have concluded that the most sensible is an indicator of whether advice encouraging the use of contraception was received or such discussions occurred in any month between the round 1 interview and the observation month (i.e., excluding the observation month itself). Under this criterion, 20 percent of the months qualify (Table 2). However, contraceptive use is far more likely when such advice was received or an encouraging discussion occurred-41 percent of such months, as against 16 percent of months not preceded by advice/discussion, this being among the largest differentials in use of modern methods found in these data. One might legitimately question the causality underlying this very strong association. While the phrasing of the questionnaire item, presented in the previous section of this paper, connotes that the advice/discussion occurred on the initiative of the health or family planning worker, by no means does the phrasing rule out contacts that were sought by the woman or her husband.

Finally, there is substantial between-community variation in use of a modern method, with the proportion of months in which a method is used ranging from a low of 12 percent in Komfoeku to a high of 35 percent in Frami.

\section{Social network measures}

A much stronger foundation for investigating the effects of social interaction on reproductive behavior is provided by the social network items; therefore we have examined a large number of indicators that can be constructed from these items. The underlying assumption is that more cumulative social exposure to attitudes and behaviors favorable to the practice of modern contraception will increase the likelihood that the woman herself uses a method. Among the social network items described in the previous section, only the item asking whether the respondent perceives that the network partner approves of modern contraception is unambiguously a measure of attitudes or behaviors favorable to contraceptive use. It is tempting to assume the same direction of effect for the question of whether or not the respondent believes the network partner has ever used a modern method, but of course it is possible that the network partner conveyed to the respondent negative aspects of that experience. The third item, on whether the respondent has discussed childbearing matters (how to avoid pregnancy, birth spacing), by no 
means specifies discussion that would be favorable to contraceptive practice. (The fourth item, asking how the respondent concluded that the network partner had used, or not used, contraception, is employed in constructing a more focused indicator of the perceived contraceptive behavior of the network partner: those respondents stating that the partner "told me" that s/he had used contraception are assumed to have more certain, and therefore more valid, perceptions.) In any case, for this analysis we begin with the hypothesis that more exposure through the respondent's social network to any one of these three - approval of modern methods, use of modern methods, discussion of childbearing matters-will increase the likelihood of the respondent's contraceptive use.

All these items were included in the social network module in round 1. In round 2 , when the name-generator was discussion of modern contraception, once again there are items on whether the network partner is perceived as approving of modern contraception and has ever used modern contraception.

For both rounds, we construct social network measures that are simple counts of the number of network partners with whom the respondent reports discussion directly relevant to contraceptive practice. We consider two sets of such counts: (a) counts from the round 1 social network data; (b) the sum of the counts from the round 1 and round 2 social network data. We refer to the second set of counts as "cumulative." The cumulative counts pertain to "unique" network partners; i.e., round 2 network partners previously reported as network partners in round 1 are excluded from the counts. ${ }^{3}$ Note that in round 2 the respondent was asked to recall conversations about modern contraception that occurred only during the 12 months preceding the survey interview. The assumption underlying the construction of the cumulative counts is that these more recent conversations add force to the earlier conversations captured in round 1. The two sets of counts are combined into one set of time-varying counts of network exposure: the round 1 counts are applied to the months from round 1 to round 2, and the sum of counts from round 1 and round 2 is applied to the subsequent months of exposure. ${ }^{4}$

The various counts - of the number of network partners who are perceived to approve of modern contraception, and so forth-are obviously constrained by the total number of partners named by the respondent. Moreover, as is evident from the first 
panels of Table 3, the likelihood of using increases with the number of network partners. Finally, there is some indication that women with a recent birth have less social interaction and are less mobile, perhaps because of child-care demands, including breastfeeding.

Table 3 Distribution of the sample and percent using modern contraception, according to round 1 social network variables

\begin{tabular}{|c|c|c|}
\hline \multirow[b]{2}{*}{ Network measures } & \multicolumn{2}{|c|}{ All network partners } \\
\hline & Distribution of sample ${ }^{a}$ & Percent using \\
\hline Total & 100.0 & 20.5 \\
\hline \multicolumn{3}{|c|}{ Number of network partners } \\
\hline 0 & 0.6 & 0.0 \\
\hline 1 & 3.4 & 10.9 \\
\hline 2 & 24.4 & 19.3 \\
\hline 3 & 33.0 & 17.0 \\
\hline 4 & 38.6 & 25.6 \\
\hline \multicolumn{3}{|c|}{$\begin{array}{l}\text { Number of network partners with whom } \\
\text { respondents discussed birth spacing, } \\
\text { pregnancy avoidance }\end{array}$} \\
\hline 0 & 31.2 & 9.0 \\
\hline 1 & 21.1 & 22.1 \\
\hline 2 & 21.2 & 26.8 \\
\hline $3-4$ & 26.5 & 27.8 \\
\hline \multicolumn{3}{|c|}{$\begin{array}{l}\text { Number of network partners who approve } \\
\text { of modern contraception }\end{array}$} \\
\hline 0 & 24.5 & 8.7 \\
\hline 1 & 19.0 & 19.9 \\
\hline 2 & 23.5 & 22.5 \\
\hline $3-4$ & 33.0 & 28.3 \\
\hline \multicolumn{3}{|c|}{$\begin{array}{l}\text { Number of network partners who use } \\
\text { a modern method }\end{array}$} \\
\hline 0 & 54.0 & 13.7 \\
\hline 1 & 24.1 & 24.3 \\
\hline 2 & 13.2 & 28.9 \\
\hline $3-4$ & 8.7 & 40.1 \\
\hline \multicolumn{3}{|c|}{$\begin{array}{l}\text { Number of network partners who use a modern } \\
\text { method and told respondent }\end{array}$} \\
\hline 0 & 58.7 & 14.2 \\
\hline 1 & 21.8 & 24.9 \\
\hline 2 & 11.8 & 31.7 \\
\hline $3-4$ & 7.8 & 39.0 \\
\hline
\end{tabular}

a The sample is 15,024 months contributed by 881 women. 
These women are also less likely to use contraception. Together, these associations can produce a spurious positive association between social interaction and contraception. For these reasons, the number of network partners is included as a control in the regression analysis below.

Patterns of contraceptive use according to the first set of counts of network partners (round 1 counts) are shown in Table 3 . The primary message in Table 3 is that, as predicted, contraceptive use is more likely among those women whose round 1 social networks contain more discussion of childbearing matters, more approval of modern contraception, and more use of modern contraception. The differentials are largest with respect to use of modern contraception by network partners, although a small fraction of observational months falls into the higher categories of this variable. Even so, the norm in Table 3 is differentials of 10 to 20 percentage points between the categories containing the majority of respondents.

Table 4 further explores some of these patterns, cross-classifying the respondent's contraceptive use by the social network measure and the number of network partners, as a means of checking whether the differentials in Table 3 reflect, in part at least, the positive association between number of network partners and contraceptive use. The patterns evident in Table 3 are essentially reproduced in the rows of Table 4, although some minor irregularities surface in the latter table.

The differentials in Tables 3 and 4 are large, and can be regarded as a first confirmation of the theory that motivates this research. A more stringent test is to estimate these effects with controls for other potentially confounding factors.

\section{REGRESSION ANALYSIS}

To control for other factors, we fit multiple regression models. As in the tabular analysis of Tables $2-4$, the unit of analysis is the woman-month and the observation time is the period from round 1 to round 4 . Excluded are months in which the woman is not in a sexual partnership and the months in which she is pregnant. The explanatory variables are a mix of fixed attributes, drawn largely from the round 1 baseline data, ${ }^{5}$ and time-varying factors measured in more than one round and, in particular, in the monthly calendars. 
Table 4 Percent of respondents using modern contraception, by number of round 1 network partners and partners' approval of use ${ }^{\mathrm{a}}$

\begin{tabular}{|c|c|c|c|c|}
\hline \multirow[b]{2}{*}{ Number of network partners } & \multicolumn{4}{|c|}{$\begin{array}{l}\text { Number of partners who approve of } \\
\text { modern contraception }\end{array}$} \\
\hline & $\mathbf{0}$ & 1 & 2 & $3-4$ \\
\hline 0 & $\begin{array}{l}0.0 \\
(88)\end{array}$ & & & \\
\hline 1 & $\begin{array}{c}0.4 \\
(235)\end{array}$ & $\begin{array}{l}19.6 \\
(280)\end{array}$ & & \\
\hline 2 & $\begin{array}{r}13.0 \\
(1280)\end{array}$ & $\begin{array}{c}26.0 \\
(860)\end{array}$ & $\begin{array}{r}20.7 \\
(1523)\end{array}$ & \\
\hline 3 & $\begin{array}{r}8.0 \\
(1168)\end{array}$ & $\begin{array}{c}16.1 \\
(898)\end{array}$ & $\begin{array}{c}19.0 \\
(972)\end{array}$ & $\begin{array}{r}21.7 \\
(1922)\end{array}$ \\
\hline \multirow[t]{2}{*}{4} & $\begin{array}{c}6.4 \\
(913)\end{array}$ & $\begin{array}{l}17.7 \\
(812)\end{array}$ & $\begin{array}{c}28.6 \\
(1033)\end{array}$ & $\begin{array}{c}32.4 \\
(3040)\end{array}$ \\
\hline & \multicolumn{4}{|c|}{$\begin{array}{l}\text { Number of partners who use a } \\
\text { modern method }\end{array}$} \\
\hline Number of network partners & $\mathbf{0}$ & 1 & 2 & $3-4$ \\
\hline 0 & $\begin{array}{c}0.0 \\
(88)\end{array}$ & & & \\
\hline 1 & $\begin{array}{c}12.1 \\
(445)\end{array}$ & $\begin{array}{c}2.9 \\
(70)\end{array}$ & & \\
\hline 2 & $\begin{array}{r}16.0 \\
(2654)\end{array}$ & $\begin{array}{c}19.5 \\
(575)\end{array}$ & $\begin{array}{l}38.7 \\
(434)\end{array}$ & \\
\hline 3 & $\begin{array}{r}9.0 \\
(2714)\end{array}$ & $\begin{array}{r}23.9 \\
(1380)\end{array}$ & $\begin{array}{l}19.4 \\
(567)\end{array}$ & $\begin{array}{l}52.2 \\
(299)\end{array}$ \\
\hline 4 & $\begin{array}{c}17.4 \\
(2209)\end{array}$ & $\begin{array}{r}27.2 \\
(1607)\end{array}$ & $\begin{array}{l}30.1 \\
(978)\end{array}$ & $\begin{array}{l}36.5 \\
(1004)\end{array}$ \\
\hline
\end{tabular}

a Sample size (woman-months) in parentheses.

\section{Model specification}

Two regression model specifications are employed. The first is a logit model of the likelihood of contraceptive use in each month in which the woman is exposed to the risk of conception. Social exposure is represented by the round 1 counts of social network partners (approving of contraception, having used contraception, and so forth). The second is a logit model that includes a fixed effect for the woman. Here social network exposure is represented by the time-varying cumulative counts. 
Logit model. The first regression model is specified as follows. Let $\mathrm{Y}_{\mathrm{it}}$ be a binary response variable representing use of modern contraception, where $t$ is a month in the period from the round 1 interview to the round 4 interview, and $\mathrm{Y}_{\mathrm{it}}=1$ if woman $i$ is using a modern method of contraception in month $t$ and $\mathrm{Y}_{\mathrm{it}}=0$ otherwise. Let $\pi_{\mathrm{it}}$ denote the probability that woman $i$ is using a modern method of contraception in month $t$ (i.e., $\pi_{\text {it }}$ $\left.=\operatorname{Prob}\left\{\mathrm{Y}_{\mathrm{it}}=1\right\}\right)$. Then the logit model can be written as:

where

$$
\mathrm{Y}_{\mathrm{it}}=\pi_{\mathrm{it}}+\varepsilon_{\mathrm{it}}
$$

$$
\operatorname{logit}\left(\pi_{\mathrm{it}}\right)=\log \left(\pi_{\mathrm{it}} / 1-\pi_{\mathrm{it}}\right)=\mathrm{X}_{\mathrm{it}} \beta+\mathrm{W}_{\mathrm{i}} \delta
$$

In this model, $\mathrm{X}_{\mathrm{it}}$ are the covariates shown in Table 2, some of which are time-varying (hence the subscript in $t$ ). The variables $\mathrm{W}_{\mathrm{i}}$ are indicators of discussion, modern method use, and approval of modern contraception by network partners, as measured in round 1; these variables are shown in Table 3. (The term $\mathrm{W}_{\mathrm{i}} \delta$ in equation (1) is intended as a general representation of social network effects, allowing for different parameterizations of these effects, as will be clear from the analysis presented below.) $\beta$ and $\delta$ are vectors of regression coefficients, and $\varepsilon_{\text {it }}$ is a disturbance term assumed to follow the extreme value distribution and to be independent of both $\mathrm{X}_{\mathrm{it}}$ and $\mathrm{W}_{\mathrm{i}}$.

Unbiased estimation of parameters $\beta$ and $\delta$ in equation (1) is jeopardized by timepersistent unmeasured variables. Of particular concern are durable aspects of a woman's preferences or her decision environment that affect her propensity to use contraceptive methods. Consider a woman who has been highly motivated to practice contraception. She might have been seeking information about the implications of such use, or, after having experimented with contraception at an earlier date, might subsequently have felt free to discuss her experiences with her social network partners. Likewise, a woman who has long lacked interest in contraception might never have discussed the subject with her network partners. When such motivations are imperfectly measured and persist over time, their effects can be partly expressed in $\mathrm{W}_{\mathrm{i}}$, the respondent's reported exposure to contraception through her social network. Of course, the $\mathrm{X}_{\mathrm{it}}$ covariates will capture many aspects of motivation to use contraception, but this will inevitably be incomplete. As a result, a correlation between the unmeasured elements of motivation and the 
$\mathrm{W}_{\mathrm{i}}$ network variables can make it appear as though these variables exert a causal effect on contraception when they are, at least in part, the product of the woman's own preferences or circumstances. A potential exists for estimation bias and mistaken inference.

We argued earlier that the nature of the round 1 inquiry into social networks should help to minimize this source of bias. Recall that the round 1 network $\mathrm{W}_{\mathrm{i}}$ is delineated by asking the respondent about others whose opinions matter to her, with the precise meaning of "matter" left to the woman to define. In other words, $\mathrm{W}_{\mathrm{i}}$ represents a general network of socially important others, rather than a set of network partners defined with respect to reproductive attitudes and behaviors. In gathering socioeconomic information on these general network partners, we also asked about their perceived attitudes toward and use of modern contraception. Had we instead asked at the outset for a listing of network partners with whom the woman had discussed contraception-as we did in round 2-the resulting social network might be regarded as the outcome of the woman's purposive information-seeking, and the risk of bias in structural modeling would certainly be greater.

In addition to the measurement strategy just described, the problem of persistent unmeasured variables can also be addressed through the regression specification. A regression model containing a fixed effect for each woman - the second type of regression model that we employ, described below-is an effective strategy for coping with time-persistent unmeasured variables. Short of the fixed-effect specification, one can acknowledge the presence of unmeasured variables specific to the woman by allowing for correlation between the disturbances $\varepsilon_{\mathrm{it}}$ and $\varepsilon_{\mathrm{is},} t \neq s$. A general, unstructured pattern of within-woman month-by-month correlation can be captured by applying the Huber correction to the standard errors of the estimated $\beta$ and $\delta$ parameters. This approach is used in the estimation of equation (1).

Logit model with fixed effects. The Huber correction does not eliminate the bias due to persistent unmeasured variables if these variables are correlated with covariates $\mathrm{X}_{\mathrm{it}}$ or $\mathrm{W}_{\mathrm{i}}$. If such correlations are believed to be present, then one strategy for recovering unbiased estimates of parameters $\beta$ and $\delta$ is to add a woman-specific effect to equation (1):

$$
\log \left(\pi_{\mathrm{it}} / 1-\pi_{\mathrm{it}}\right)=\mathrm{X}_{\mathrm{it}} \beta+\mathrm{W}_{\mathrm{it}} \delta+\mathrm{u}_{\mathrm{i}}
$$


where $\mathrm{u}_{\mathrm{i}}$ is a vector containing an effect on contraceptive use for each woman $i$ and all $\mathrm{X}$ and $\mathrm{W}$ are subscripted in $t$ (i.e., are time-varying). Equation (2) can be regarded as an extreme response to concerns about woman-specific omitted variables: this specification allows each woman to have her own proclivity to use contraception, beyond whatever is due to the measured explanatory variables $X_{i t}$ and the social network variables $\mathrm{W}_{\mathrm{i}}$. Estimation of this model comes with some costs, discussed below, but it has considerable appeal when there is reason to expect bias resulting from woman-specific unmeasured variables. If a woman's time-invariant characteristics affect contraceptive use and are also correlated with social network exposure, the fixed-effect specification of equation (2) removes these effects, in so doing purging the estimated $\delta$ of this source of bias. It is a powerful and tidy solution. ${ }^{6}$

Nonetheless, a number of shortcomings are associated with the fixed-effects approach. The woman-specific effects $u_{i}$ are perfectly correlated with any variables that are unchanging over the observation period. This means that only women whose contraceptive status changes between round 1 and round 4 can contribute to the estimation of equation (2) - 200 women out of the 881 women initially selected for the analysis. Furthermore, any explanatory variables that take on the same value in the period from round 1 to round 4 contribute nothing to the estimation of equation (2) and drop out of the analysis. These include variables that are intrinsically fixed (e.g., school attainmentfor almost all Ghanaians fixed by age 20) as well as variables that could vary over the observation period but were measured just once (e.g., perceived fecundability, household possessions, and many other variables among the covariates $\mathrm{X}_{\mathrm{i}}$ ). By definition, explanatory variables that are intrinsically fixed make no contribution under the fixedeffects specification; their effects are fully subsumed by the woman-specific effects $u_{i}$. The same cannot be said of variables that are not intrinsically invariant over time, but only appear to be so owing to decisions of investigators not to repeat questionnaire items in multiple rounds. The resulting shrinkage in the set of confounding covariates $X_{i}$ in equation (2) is, everything else being equal, undesirable from the standpoint of obtaining valid estimates of the social network effects $\delta$. Offsetting these drawbacks of the fixed-effects approach is its effectiveness in eliminating bias due to the effects of persis- 
tent unmeasured characteristics of the woman, in particular her motivation to avoid pregnancy, a difficult variable to measure fully and accurately in a survey interview.

\section{Results from the regression analysis}

Benchmark results. Before estimating equations (1) and (2), we estimate a logit model with the conventional covariates only, excluding the social network variables. This "benchmark" model is a reference point for later estimates that incorporate the network measures. The estimates of this model are presented in Table 5. The logit coefficients are shown in the left-hand column of the table; underneath each coefficient is a Z-statistic, calculated using the Huber correction for persistent woman-specific unobservables. The right-hand column reports the predicted change in the percentage using a modern contraceptive method that is associated with the covariate in question. All of the covariates are entered as dummy variables, and the predicted change for a given covariate should be interpreted as the change in use given that the other covariates are fixed at their sample means.

The exposure, fecundability, and preference variables for the most part show expected effects. The woman's self-reported ability to conceive remains a good predictor of modern method use; women who say that they have difficulty conceiving are some 5.4 percentage points less likely to use a modern contraceptive, other things being held constant. As expected, the absence of a spouse for more than half of month $t$ is negatively associated with method use in that month, and months in which women are practicing postpartum abstinence are also months of markedly lower method use (16.3 percentage points less). ${ }^{7}$ Net of the other variables, a woman's expressed desire to limit or postpone childbearing is a significant predictor in the expected direction. The coefficients indicate that contraceptive use for terminating childbearing is slightly more common than use for birth spacing, perhaps a surprising pattern in a West African population. A woman's perception of her husband's desire to limit or postpone births is also significant. Reports of health problems in the past year are negatively associated with method use, and when the problem is serious it is a statistically significant predictor of method use. 
Table 5 Use of modern contraception: Results from baseline logit model (robust IZI statistics in parentheses)

\begin{tabular}{lcc}
\hline Explanatory variable and category & $\begin{array}{c}\text { Use of modern } \\
\text { contraception }\end{array}$ & $\begin{array}{c}\text { Predicted change } \\
\text { in percent using }\end{array}$ \\
\hline Constant & -1.668 &
\end{tabular}

Exposure, fecundity, fertility preferences, and health

Age $^{\text {a }}$

$25-29$
$30-34$
$35-39$
$40-44$
$>44$

$\begin{array}{cc}-0.118 & -1.5 \\ (0.49) & \\ -0.078 & -1.0 \\ (0.27) & \\ 0.248 & 3.7 \\ (0.89) & \\ -0.938 & -9.3 \\ (2.57) & \\ -0.695 & -7.4 \\ (1.75) & \\ -0.451 & -5.4 \\ (2.38) & \\ -2.298 & -16.3 \\ (9.03) & \\ -0.328 & -3.6 \\ (1.74) & \end{array}$

Woman's desire for more children ${ }^{\mathrm{b}}$

Wants more later $\quad 0.699$

6.9

$(2.65)$

Wants no more $\quad 0.916$

9.9

(3.57)

Husband's desire for more children ${ }^{\text {b }}$

Wants more later $\quad 0.353$

$(1.67)$

Wants no more $\quad 0.592$

(2.75)

Health problems in reference period

Mild

$-0.254$

$-3.2$

Severe

$-0.798$

$-8.4$

(4.32)

Social and economic variables

Woman's schooling

Primary ${ }^{\mathrm{c}}$

$-0.164$

$-1.9$

Middle or higher

(0.70)

0.022

(0.09)

0.3 
Table 5 (continued)

\begin{tabular}{|c|c|c|}
\hline Explanatory variable and category & $\begin{array}{l}\text { Use of modern } \\
\text { contraception }\end{array}$ & $\begin{array}{l}\text { Predicted change } \\
\text { in percent using }\end{array}$ \\
\hline \multicolumn{3}{|l|}{ Husband's schooling } \\
\hline Primary $^{c}$ & $\begin{array}{r}0.609 \\
(1.21)\end{array}$ & 8.6 \\
\hline Middle & $\begin{array}{c}0.098 \\
(0.47)\end{array}$ & 1.2 \\
\hline Secondary or higher & $\begin{array}{r}0.107 \\
(0.38)\end{array}$ & 1.3 \\
\hline \multicolumn{3}{|l|}{ Household economic index (quartile) ${ }^{\mathrm{d}}$} \\
\hline Second & $\begin{array}{c}0.168 \\
(0.61)\end{array}$ & 1.7 \\
\hline Third & $\begin{array}{r}0.361 \\
(1.23)\end{array}$ & 3.9 \\
\hline Fourth & $\begin{array}{r}0.680 \\
(2.02)\end{array}$ & 8.3 \\
\hline \multicolumn{3}{|l|}{ Mass media, urban experience, and program contact } \\
\hline Reads newspaper in reference period & $\begin{array}{c}-0.371 \\
(1.34)\end{array}$ & -4.1 \\
\hline $\begin{array}{l}\text { Listens to radio at least once a week } \\
\text { in reference period }\end{array}$ & $\begin{array}{c}0.174 \\
(1.18)\end{array}$ & 2.1 \\
\hline Visited Accra during reference period & $\begin{array}{r}0.232 \\
(1.38)\end{array}$ & 2.8 \\
\hline Visited other cities during reference period & $\begin{array}{c}0.161 \\
(1.06)\end{array}$ & 0.1 \\
\hline $\begin{array}{l}\text { Received contraceptive advice from health or family } \\
\text { planning worker, round } 1 \text { through previous month }\end{array}$ & $\begin{array}{r}1.079 \\
(6.35)\end{array}$ & 16.3 \\
\hline \multicolumn{3}{|l|}{ Community } \\
\hline Abuesi ${ }^{\mathrm{e}}$ & $\begin{array}{c}-1.183 \\
(3.44)\end{array}$ & -17.2 \\
\hline Amanfro & $\begin{array}{c}-0.862 \\
(2.39)\end{array}$ & -13.8 \\
\hline Brenu & $\begin{array}{c}-0.848 \\
(2.52)\end{array}$ & -13.6 \\
\hline Komfoeku & $\begin{array}{c}-1.513 \\
(4.88)\end{array}$ & -20.0 \\
\hline Tubaman & $\begin{array}{c}-0.784 \\
(2.11)\end{array}$ & -12.8 \\
\hline
\end{tabular}

Note: The sample is 15,024 months contributed by 881 women.

a Omitted category: under age 25 b Omitted category: wants more soon c Omitted category: no schooling

d Omitted category: first quartile e Omitted category: Frami 
Turning to the social and economic variables, a woman's schooling shows even less predictive power in the logit regressions than in the bivariate analysis of Table 2. This is not entirely unexpected, given other evidence from Ghana and elsewhere in West Africa. Jejeebhoy (1995), reviewing survey data from the 1970s and 1980s, notes that the association between schooling and fertility appears to be weak in West Africa (and, where it exists, often does not follow a simple inverse pattern). That this would continue to be the case in the late 1990s in these Ghanaian data is nevertheless surprising, in light of the strong association observed in recent years in most developing countries between women's schooling and the use of modern methods of contraception (Diamond et al. 1999). One explanation for the weak effect of schooling may be the inclusion of other variables that mediate the effect of schooling on contraception, such as mass media exposure. The schooling of the husband performs almost as poorly as an explanatory variable. There is some suggestion in these data that a husband's primary schooling has an effect on contraceptive practice (an increase of 8.6 percentage points in modern method use, as compared to husbands with no schooling), but the effect does not test as significant and, further, the coefficients for higher levels of schooling are much smaller in size. The poor performance of the husband's schooling may be explained by the control for household economic wealth. As expected, the latter variable has a positive effect on contraceptive use, and the estimated effect is large: contraceptive use is 8.3 percentage points higher for women in the fourth quartile compared with the first quartile, net of other variables.

Although one might have expected regular exposure to mass media and travel to urban areas to exert some influence, neither of these measures shows empirical strength. Women who listen regularly to the radio are no more likely than other women to use modern methods; nor are women who have traveled in the past year to Accra or other cities. In contrast, receiving encouraging advice from a health or family planning worker is strongly associated with use of modern contraception; however, as indicated above, there is some ambiguity about the direction of causality underlying this association.

Finally, with controls for all the above variables, use of a modern contraceptive method is most likely in Frami and least likely in Komfoeku and Abuesi, just as in the bivariate tabulations in Table 2. 
Effects of the social network variables: logit model. Table 6 summarizes the results of a number of specifications using the social network data. We present only the estimated network effects here, although these are taken from equations including all of the $\mathrm{X}_{\mathrm{it}}$ covariates listed in Table 5. The coefficients of the $\mathrm{X}_{\mathrm{it}}$ covariates are scarcely affected by the inclusion of the social network measures $\mathrm{W}_{\mathrm{i}}$. All of the equations also include a control for the total number of network partners, a variable that is positively

Table 6 Estimated effects from logit regressions of round 1 social network variables on use of modern contraception

\begin{tabular}{|c|c|c|}
\hline Network measures & $\begin{array}{c}\text { Predicted } \\
\text { percent using }\end{array}$ & $\begin{array}{c}\text { Robust }|\mathrm{Z}| \\
\text { statistic }\end{array}$ \\
\hline \multicolumn{3}{|c|}{$\begin{array}{l}\text { Number of network partners with whom respondent } \\
\text { discussed birth spacing, pregnancy avoidance }\end{array}$} \\
\hline 0 & 13 & \\
\hline 1 & 22 & 2.93 \\
\hline 2 & 24 & 3.67 \\
\hline $3-4$ & 23 & 3.49 \\
\hline \multicolumn{3}{|l|}{$\left(\chi_{3}^{2}=16.0, p\right.$-value $\left.=0.001\right)$} \\
\hline \multicolumn{3}{|c|}{ Number of network partners who approve of modern contraception } \\
\hline 0 & 13 & \\
\hline 1 & 20 & 2.33 \\
\hline 2 & 22 & 2.87 \\
\hline $3-4$ & 23 & 3.48 \\
\hline \multicolumn{3}{|l|}{$\left(\chi_{3}^{2}=12.0, p\right.$-value $\left.=0.007\right)$} \\
\hline \multicolumn{3}{|c|}{ Number of network partners who use a modern method } \\
\hline 0 & 16 & \\
\hline 1 & 23 & 2.50 \\
\hline 2 & 23 & 2.17 \\
\hline $3-4$ & 31 & 3.68 \\
\hline \multicolumn{3}{|l|}{$\left(\chi_{3}^{2}=15.0, p-\right.$ value $\left.=0.002\right)$} \\
\hline \multicolumn{3}{|c|}{ Number of network partners who use a modern method and told respondent } \\
\hline 0 & 16 & \\
\hline 1 & 23 & 2.62 \\
\hline 2 & 25 & 2.54 \\
\hline $3-4$ & 31 & 3.41 \\
\hline$\left(\chi_{3}^{2}=15.5, p\right.$-value $\left.=0.002\right)$ & & \\
\hline
\end{tabular}

Notes: The sample is 15,024 months contributed by 881 women. The equations include the full set of covariates listed in Table 5 and the number of network partners. The predicted percentages are based on the average values of predictions, with all covariates (except for the network variables) varying over the sample. The number of network partners is positively associated with modern method use, and is significant at the 0.05 level in all models. 
associated with method use. The network effects, expressed as the predicted percentage using a modern method, are shown in the first column of the table; the second column reports the Z-statistics based on robust standard errors. ${ }^{8}$ The predicted percentages from four equations are presented in Table 6 , a separate equation for each of the four network variables already examined in Table 3.

The most striking aspect of Table 6 is the uniformity of results. Across all models, an increase in the number of network partners is associated with statistically significant and substantively large increases in use of modern contraception. Indeed, by either criteria - statistical significance or the magnitude of effects - the social network variables are the most powerful explanatory variables in these regressions. Among the four network variables, the largest effects are due to perceived network partner use of modern contraception (bottom two panels of the table). In these panels, the gap in the respondent's contraceptive use according to her reports of the behavior in her network is as wide as 15 percentage points (contrasting the predicted percentage when no network partners use to the predicted percentage when three or four partners use). Other differentials are smaller but still substantial, ranging between 10 and 15 percentage points.

A common feature of the pattern of predicted percentages in Table 6 is that the largest differential in contraceptive use is between women with zero and one network partner. Indeed, in the first two panels, the gain in contraceptive use beyond one network partner appears to be negligible. This suggests that the effects of the social network variables might be captured more parsimoniously than the effects of the full set of dummy variables in the equation underlying the predicted percentages in Table 6 . The pattern in Table 6 suggests that an appropriate parameterization would consist of one effect for the contrast between zero and one network partner and a second effect for each additional partner beyond one (i.e., a slope for the range of two to four network partners). We have estimated equations with this specification of the effects of the network variables (results not shown here). ${ }^{9}$ This additional analysis confirms our interpretation of the pattern of predicted percentages in Table 6. The effect of these social network variables on contraceptive use is highly nonlinear, the dominant feature being the contrast between zero and one (or more) network partner. This effect is substantively large 
and statistically significant for all four network variables. The additional effect of each network partner beyond one is small and not statistically significant, with the exception of network partners' approval of contraception, where this slope is barely significant at the 0.05 level.

That the social network variables have a substantial effect if a woman's network includes one person facilitating contraceptive use but little additional effect if additional network partners facilitate use has salient implications for the overall impact of diffusion effects on contraceptive use in this population. Further analysis using dynamic simulations is required to assess these implications more fully. For now we simply posit that nonlinear effects of this form - the largest gain due to exposure through merely one network partner - are conducive to especially rapid social contagion effects: that is, this pattern suggests a very low "tipping point" (Gladwell 2000). In fact, a disproportionate impact on the diffusion of innovative attitudes and behavior among a small vanguard is a common finding in the empirical literature (Degenne and Forsé 1999). For example, in research with objectives and design closely resembling the Cape Coast analysis reported here, Behrman et al. (2001) estimate nonlinear effects of social network variables on contraceptive use in Kenya that are strikingly similar in form to those shown in Table 6. Effects of the social network variables: fixed-effects logit model. We now examine the effects of social network variables for cumulative experience over rounds 1 and 2 . The cumulative variables are of interest in their own right and, more importantly for our purposes, permit estimation of regression models containing a fixed effect for the woman.

Table 7 shows the pattern of contraceptive use according to the cumulative social network measures. Consistent with our earlier results (Table 3), contraceptive use is higher among women whose social networks engage in more discussion of childbearing matters and show greater approval and use of modern contraception. To continue the comparison with the previous analysis of effects of the round 1 social network variables, we replicate the regression analysis of Table 6 in Table 8 for the cumulative round 1 and round 2 network variables. The pattern of effects in Table 8 closely resembles the pattern in Table 6, with a large contrast in contraceptive use between those with zero and one network partner and modest gains from additional network partners beyond one. 
Table 7 Distribution of the sample and percent using modern contraception, according to cumulative social network variables in rounds 1 and 2

\begin{tabular}{|c|c|c|}
\hline Network measures & Distribution of sample $^{\mathrm{a}}$ & Percent using \\
\hline \multicolumn{3}{|c|}{$\begin{array}{l}\text { Cumulative number of network partners with whom } \\
\text { respondent discussed birth spacing, pregnancy avoidance }\end{array}$} \\
\hline 0 & 21.0 & 6.7 \\
\hline 1 & 17.4 & 14.5 \\
\hline 2 & 18.9 & 26.6 \\
\hline 3 & 18.8 & 28.7 \\
\hline 4 & 12.0 & 23.6 \\
\hline $5-8$ & 12.0 & 27.8 \\
\hline \multicolumn{3}{|c|}{$\begin{array}{l}\text { Cumulative number of network partners who } \\
\text { approve of modern contraception }\end{array}$} \\
\hline 0 & 17.9 & 5.8 \\
\hline 1 & 15.2 & 16.2 \\
\hline 2 & 21.3 & 23.0 \\
\hline 3 & 19.9 & 23.3 \\
\hline 4 & 14.0 & 25.3 \\
\hline $5-8$ & 11.6 & 33.8 \\
\hline \multicolumn{3}{|c|}{$\begin{array}{l}\text { Cumulative number of network partners who use } \\
\text { a modern method }\end{array}$} \\
\hline 0 & 40.4 & 10.2 \\
\hline 1 & 25.8 & 24.1 \\
\hline 2 & 16.0 & 24.1 \\
\hline 3 & 11.6 & 34.2 \\
\hline 4 & 4.4 & 34.2 \\
\hline $5-8$ & 2.5 & 41.4 \\
\hline \multicolumn{3}{|c|}{$\begin{array}{l}\text { Cumulative number of network partners who use } \\
\text { a modern method and told respondent }\end{array}$} \\
\hline 0 & 44.2 & 11.3 \\
\hline 1 & 23.9 & 23.3 \\
\hline 2 & 15.8 & 26.2 \\
\hline 3 & 10.5 & 36.5 \\
\hline 4 & 3.4 & 31.4 \\
\hline $5-8$ & 2.2 & 42.2 \\
\hline
\end{tabular}

Note: The sample is 15,024 months contributed by 881 women.

As we argued above, the validity of the estimated effects of the social network variables in Tables 6 and 8 is jeopardized by the presence of persistent unmeasured characteristics of a woman, for example her motivation to control her fertility. Such unmeasured characteristics might make a woman both more likely to use modern con- 
Table 8 Estimated effects from logit regressions of cumulative round 1 and 2 social network variables on use of modern contraception

\begin{tabular}{|c|c|c|}
\hline Network measures & $\begin{array}{c}\text { Predicted } \\
\text { percent using }\end{array}$ & $\begin{array}{c}\text { Robust }|\mathrm{Z}| \\
\text { statistic }\end{array}$ \\
\hline \multicolumn{3}{|c|}{$\begin{array}{l}\text { Cumulative number of network partners with whom } \\
\text { respondent discussed birth spacing, pregnancy avoidance }\end{array}$} \\
\hline 0 & 12 & \\
\hline 1 & 19 & 2.00 \\
\hline 2 & 25 & 3.78 \\
\hline 3 & 25 & 3.56 \\
\hline 4 & 20 & 2.22 \\
\hline $5-8$ & 19 & 1.62 \\
\hline \multicolumn{3}{|l|}{$\left(\chi_{5}^{2}=19.5, p\right.$-value $\left.=0.002\right)$} \\
\hline \multicolumn{3}{|c|}{$\begin{array}{l}\text { Cumulative number of network partners who approve of } \\
\text { modern contraception }\end{array}$} \\
\hline 0 & 10 & \\
\hline 1 & 19 & 2.89 \\
\hline 2 & 23 & 4.36 \\
\hline 3 & 20 & 3.01 \\
\hline 4 & 22 & 3.37 \\
\hline $5-8$ & 26 & 3.64 \\
\hline \multicolumn{3}{|l|}{$\left(\chi_{5}^{2}=21.0, p\right.$-value $\left.=0.001\right)$} \\
\hline \multicolumn{3}{|c|}{ Cumulative number of network partners who use a modern method } \\
\hline 0 & 14 & \\
\hline 1 & 23 & 3.34 \\
\hline 2 & 21 & 2.57 \\
\hline 3 & 26 & 3.20 \\
\hline 4 & 26 & 2.57 \\
\hline $5-8$ & 27 & 2.17 \\
\hline \multicolumn{3}{|c|}{$\left(\chi_{5}^{2}=15.6, p\right.$-value $\left.=0.008\right)$} \\
\hline \multicolumn{3}{|c|}{$\begin{array}{l}\text { Cumulative number of network partners who use a } \\
\text { modern method and told respondent }\end{array}$} \\
\hline 0 & 15 & \\
\hline 1 & 23 & 3.16 \\
\hline 2 & 22 & 2.52 \\
\hline 3 & 29 & 3.57 \\
\hline 4 & 22 & 1.44 \\
\hline $5-8$ & 29 & 2.10 \\
\hline$\left(\chi_{5}^{2}=16.8, p\right.$-value $\left.=0.005\right)$ & & \\
\hline
\end{tabular}

Notes: The sample is 15,024 months contributed by 881 women. The number of network partners is time-varying, being equal to the round 1 value until the round 2 interview, and thereafter equaling the sum of the round 1 and round 2 values. All equations include the full set of covariates listed in Table 5 and the number of network partners. The predicted percentages are based on the average values of predictions, with all covariates (except for the network variables) varying over the sample. The number of network partners is positively associated with modern method use, and is significant at the 0.05 level in all equations. 
traception and more likely to report social interaction about childbearing and contraception. If so, this would then be expressed in estimated effects of the social network variables on contraception that are not true causal effects but rather reflect the unmeasured variables. Equations containing a time-invariant effect for each woman are an effective strategy for removing this possibility.

Coefficients for the social network variables (cumulative round 1 and round 2 variables) from the fixed-effect logit model are presented in Table 9 (right-hand column). ${ }^{10}$ In these regressions, the social network variables are entered as continuous variables, in contrast to the categorical treatment in previous tables. When the regression contains a fixed effect for each woman, the effects of the remaining variables in the equation can be viewed as describing within-woman processes-for example, the response of contraceptive behavior to changes in social network exposure to contraception. Within-woman changes in the social network measures are far more limited than the range of categories used for these measures in previous tables, with most women adding merely one or two more network partners at round 2 . The coefficients on the continuous variables shown in Table 9 represent the effects of exposure to one additional network partner. For purposes of comparison, the regressions of Table 8 are re-

Table 9 Estimates of the effects of social networks on use of modern contraception, without and with fixed effects

\begin{tabular}{lcc}
\hline Network measures & $\begin{array}{c}\text { Without } \\
\text { fixed effects }\end{array}$ & $\begin{array}{c}\text { With } \\
\text { fixed effects }\end{array}$ \\
\hline Number of network partners with whom respondent & 0.116 & 0.131 \\
discussed birth spacing, pregnancy avoidance & $(2.09)$ & $(1.20)$ \\
Number of network partners who approve of & 0.176 & 0.893 \\
modern contraception & $(2.98)$ & $(1.39)$ \\
Number of network partners who use a modern method & 0.223 & 0.531 \\
& $(3.26)$ & $(1.71)$ \\
Number of network partners who use a modern method & 0.231 & 0.643 \\
and told respondent & $(3.34)$ & $(2.08)$ \\
\hline
\end{tabular}

Notes: For the fixed-effects model the sample is 3,605 months contributed by 200 women. The figures are coefficients for the specified network measure, entered as a continuous variable. Robust Z-statistics are in parentheses. The number of network partners is time-varying, being equal to the round 1 value until the round 2 interview, and thereafter equaling the sum of the round 1 and round 2 values. All equations include those covariates listed in Table 5 that are time-varying. 
estimated with the social network measures entered as continuous measures and are shown in the left-hand column of Table 9.

The estimates from the fixed-effect regressions in Table 9 largely corroborate the findings from the logit model in Table 6. The first two network measures-discussion of childbearing and approval of contraception by network partners-do not test as significant under the fixed-effect specification (note Z-statistics in parentheses). A woman's belief that her network partners use modern contraception, however, continues to show a positive effect on the likelihood that the respondent herself uses modern contraception. Indeed, these coefficients are two to three times larger under the fixed-effects specification. (Not too much should be made of the relative magnitudes of the two sets of coefficients, however, because the effects under the non-fixed-effect specification are highly nonlinear.) In short, the results from the fixed-effect regressions indicate that greater exposure to the contraceptive behavior of other persons increases the likelihood of practicing contraception.

\section{CONCLUSIONS}

We have presented results from a multi-round longitudinal investigation into the effects of social learning and social influence on reproductive behavior in southern Ghana. By suggesting that information exchange among network partners and the perception of partner behavior can be important influences on individual reproductive decisions, the results for the measured social network variables broadly support "diffusionist theory" (Casterline 2001). To be sure, much remains to be done to test the strength of these effects against alternative causal interpretations. In view of the skepticism expressed by some methodologists (e.g., Manski 1993; Durlauf and Walker 2001), a full battery of tests is required before the estimates can be judged credible. Nevertheless, the results reported here-drawing on four rounds of survey data, covering two years of reproductive experience, and employing stringent test criteria (the fixed-effects model)—are promising indeed.

The social network coefficients that we have estimated are highly significant by statistical criteria, and their estimated effects on contraceptive use are large in magni- 
tude. They are robust to the inclusion of a number of measures of individual attitudes and reproductive circumstances, and they hold their own in the fixed-effects regression specification, which would have been expected to weaken the estimated effects of network variables on contraception if persistent unobservable factors were the full explanation for these effects. In short, the results strongly confirm the theory that has motivated this research: adoption of modern contraception - innovative reproductive behavior in southern Ghana - is affected by exposure to the reproductive attitudes and behaviors of other persons through informal social interaction. The net effect of this social exposure is strongly positive. (This outcome does not rule out negative social network effects among a subset of women-e.g., discussion of health side effects that discourages contraceptive use.) The process of reproductive change that these results imply can be loosely described as "social contagion."

Even more stringent criteria can be applied as our fieldwork in Ghana proceeds. Three more rounds of data collection beyond the data analyzed in this paper, covering an additional 18 to 21 months of experience, are either completed or planned. The additional data will provide a longer time series of information on women's reproductive behavior and social interaction, as well as more detail on the role of husbands and their social networks.

The Cape Coast data also offer opportunities to refine the specification of the effects of exposure to contraceptive attitudes and behaviors via social network partners. In particular, the present analysis takes no account of demographic and socioeconomic characteristics of the network partners. The Cape Coast data contain considerable information on each named network partner: residence, schooling, ethnicity, age, marital status, kinship relationship to respondent, and frequency of contact with respondent. The respondent was also asked to name the network partner whose views and opinions are most important to her. In principle, variables such as these can be employed as conditioning factors that serve to differentially weight the contraceptive information obtained about each partner. We examined several of the weighting schemes that seem most compelling on theoretical grounds, but found that these provide no additional explanatory power. ${ }^{11}$ This is our first exploration of more complex social network specifi- 
cations, based on the first two years of panel survey observation. It would be premature to conclude that more complex specifications that take into account the characteristics of network partners will not prove more revealing of the nature of social network effects.

Furthermore, the Cape Coast data reveal that, as expected, social networks in southern Ghana are structured in terms of social, economic, and other factors. This suggests another means by which social and economic variables can influence reproductive behavior, namely by determining the composition of individuals' social networks (shown in this paper to be powerful determinants of contraceptive use). As we have previously argued (Montgomery and Casterline 1996), little is to be gained by setting socioeconomic effects and social interaction effects in opposition to each other, because ultimately the two sets of effects are closely bound together.

\section{NOTES}

This research was supported by awards to the Policy Research Division of the Population Council from the National Institute of Child Health and Human Development (R01-HD34524), the Mellon Foundation, and the Hewlett Foundation; and by an award to the University of Cape Coast from the Rockefeller Foundation. The authors gratefully acknowledge the many contributions to this research from its inception in 1998 provided by Steven Green and William Adih. This is a revision of a paper presented at the Annual Meeting of the Population Association of America, March 2001.

1 Professor Dominic Agyeman is the principal investigator at the University of Cape Coast, and Peter Aglobitse is a coinvestigator.

2 These are sexual partnerships that are socially recognized unions and do not include informal sexual liaisons. In this setting there can be ambiguity about whether a union constitutes a "marriage." In the survey fieldwork, a deliberate effort is made to use terminology that refers to stable and socially sanctioned sexual partnerships.

3 Among the network partners named in round 2 by the 881 women analyzed in this paper, 39 percent were also named in round 1 . 
4 We also constructed social network measures that were counts restricted to network partners who are "confidants" of the respondent. The expectation was that the effects of exposure to the attitudes and behaviors of close friends- "confidants"-would be stronger than the effects of exposure to all network partners. In the event, this expectation was not borne out: the results resemble those reported below for all network partners; indeed if anything, the effects are smaller when the social network count is limited to confidants.

5 We have included two variables measured in later rounds, the woman's health status (round 2) and the household economic index (round 3). The reference period for the first of these variables - whether the woman experienced health problems during the past year-extends further back in time than the round 1 interview, but also admits reports of health problems that developed between rounds 1 and 2 and after the month $t$ in which contraceptive use is measured. We did not ask about the precise timing of health problems. The household economic index, an indicator of household wealth, is assumed to be relatively unchanging over the two-year observation period for this analysis.

6 In earlier research on diffusion effects on fertility (Montgomery and Casterline 1993) using aggregate-level, time-series, cross-section data for Taiwan, we employed an analogous regression specification that included fixed effects for the observational units (administrative townships). In that analysis, we were able to supplement the fixed-effects strategy with the use of instrumental variables for the social exposure variables, thereby further strengthening our capacity to eliminate omitted-variable bias.

7 There is enough overlap of postpartum abstinence and modern method use to justify treating months of abstinence as months in which the woman might use a modern method. In preliminary work, we also examined the influence of breastfeeding, another time-varying variable, but found it to have no significant influence once postpartum abstinence status is controlled. 
8 The network coefficients are robust to the exclusion of several powerful $X_{\text {it }}$ covariates: advice from a health or family planning worker; a woman's desire to terminate or postpone births; her health status; and the household economic index.

9 The specification is usually termed "piecewise":

$$
\log \left(\pi_{\mathrm{it}} / 1-\pi_{\mathrm{it}}\right)=\mathrm{X}_{\mathrm{it}} \beta+\delta_{\mathrm{i}} \mathrm{W}_{1 \mathrm{t}}+\delta_{2}\left(\mathrm{~W}_{1 \mathrm{t}}-1\right) \mathrm{W}_{2 \mathrm{t}}
$$

where $\mathrm{W}_{1 \mathrm{t}}$ is the number of network partners (who discussed, approved, etc.) and $\mathrm{W}_{2 \mathrm{t}}$ is an indicator variable that equals 1 if $\mathrm{W}_{1 \mathrm{t}}>1,0$ otherwise. The coefficients of key interest are $\delta_{1}$ and $\left(\delta_{1}+\delta_{2}\right)$. $\delta_{1}$ is the effect on the use of modern contraception of having one as against zero network partners, and $\left(\delta_{1}+\delta_{2}\right)$ is the effect on contraceptive use of each additional network partner beyond one.

10 We do not calculate predicted probabilities. When estimating a fixed-effect logit, ordinarily the vector of coefficients $u_{i}$ is not explicitly calculated. The "conditional logit" approach developed by Chamberlain (1980) permits the estimation of all other parameters in the equation assuming the presence of the $u_{i}$ without directly observing them. Interpretable predicted probabilities cannot be calculated without first recovering the $\mathrm{u}_{\mathrm{i}}$, and this step is not straightforward.

11 Furthermore, as mentioned in note 4, we replicated the analysis presented here with the counts of network partners limited to partners said to be "confidants" of the respondent, with the aim of taking into account a characteristic of network partners that might condition the strength of the effects of their attitudes and behaviors on the respondent's contraceptive use. In the event, the results closely resemble those shown here; if anything, the effects of these alternative social network variables are weaker.

\section{REFERENCES}

Adibo, M. 1992. "Conceptions and misconceptions: Community views on family planning.” Technical Report, Health Research Unit, Ministry of Health, Accra, Ghana. 
Adongo, Philip B. et al. 1997. "Cultural factors constraining the introduction of family planning among the Kassena-Nankana of northern Ghana," Social Science and Medicine 45(12): 1789-1804.

Agyeman, Dominic K. et al. 1996. "Social structure and the diffusion of fertility behavior." Final Report submitted to the Rockefeller Foundation.

Behrman, Jere R., Hans-Peter Kohler, and Susan Cotts Watkins. 2001. "Social networks, family planning and worrying about AIDS: What are the network effects if network partners are not determined randomly?" paper presented at the Annual Meeting of the Population Association of America, March.

Bledsoe, Caroline H., Fatoumatta Banja, and Allan G. Hill. 1998. "Reproductive mishaps and Western contraception: An African challenge to fertility theory," Рориlation and Development Review 24(1): 15-57.

Bledsoe, Caroline, Allan G. Hill, Umberto D’Alessandro, and Patricia Langerock. 1994. "Constructing natural fertility: The use of Western contraceptive technologies in rural Gambia," Population and Development Review 20(1): 81-113.

Bongaarts, John and Judith Bruce. 1995. "The causes of unmet need for contraception and the social content of services," Studies in Family Planning 26(2): 57-75.

Bongaarts, John and Susan Cotts Watkins. 1996. "Social interactions and contemporary fertility transitions," Population and Development Review 22(4): 639-682.

Caldwell, John C., I.O. Orubuloye, and Pat Caldwell. 1992. "Fertility decline in Africa: A new type of transition?" Population and Development Review 18(2): 211-242.

Carley, Kathleen M. 2001. "Learning and using new ideas: A sociocognitive perspective," pp. 179-207 in John B. Casterline (ed.), Diffusion Processes and Fertility Transition: Selected Perspectives. Washington, DC: National Academy Press.

Casterline, John B. 2001. "Diffusion processes and fertility transition: Introduction," pp. 1-38 in John B. Casterline (ed.), Diffusion Processes and Fertility Transition: Selected Perspectives. Washington, DC: National Academy Press. 
Casterline, John B. and Steven W. Sinding. 2000. "Unmet need for family planning in developing countries and implications for population policy," Population and Development 26(4): 691-723.

Chamberlain, Gary. 1980. "Analysis of covariance with qualitative data," Review of Economic Studies 47: 225-238.

Cleland, John. 2001. "Potatoes and pills: An overview of innovation-diffusion contributions to the explanations of fertility decline," pp. 39-65 in John B. Casterline (ed.), Diffusion Processes and Fertility Transition: Selected Perspectives. Washington, DC: National Academy Press.

Degenne, Alain and Michel Forsé. 1999. Introducing Social Networks. London: Sage Publications.

Diamond, Ian, Margaret Newby, and Sarah Varle. 1999. "Female education and fertility: Examining the links," pp. 23-48 in Caroline H. Bledsoe, John B. Casterline, Jennifer A. Johnson-Kuhn, and John G. Haaga (eds.), Critical Perspectives on Schooling and Fertility in the Developing World. Washington, DC: National Academy Press.

Durlauf, Steven N. and James R. Walker. 2001. "Social interactions and fertility transitions," pp. 115-137 in John B. Casterline (ed.), Diffusion Processes and Fertility Transition: Selected Perspectives. Washington, DC: National Academy Press.

Entwisle, Barbara and Jenny Godley. 1998. "Village networks and patterns of contraceptive choice," paper presented at the National Academy of Sciences workshop on the Social Dynamics of Fertility Change in Developing Countries, Washington, DC.

Entwisle, Barbara, Ronald R. Rindfuss, David K. Guilkey, Aphichat Chamratrithirong, Sara R. Curran, and Yothin Sawangdee. 1996. "Community and contraceptive choice in rural Thailand: A case study of Nang Rong," Demography 33: 1-11.

Ghana Statistical Service (GSS) and Macro International Inc. (MI). 1999. Ghana Demographic and Health Survey 1998. Calverton, MD: GSS and MI. 
Gladwell, Malcolm. 2000. The Tipping Point: How Little Things Can Make a Big Difference. Boston: Little, Brown.

Hornik, Robert and Emile McAnany. 2001. "Mass media and fertility change," pp. 208239 in John B. Casterline (ed.), Diffusion Processes and Fertility Transition: Selected Perspectives. Washington, DC: National Academy Press.

Jejeebhoy, Shireen J. 1995. Women's Education, Autonomy, and Reproductive Behaviour: Experience from Developing Countries. Oxford: Clarendon Press.

Knodel, John and Etienne van de Walle. 1979. "Lessons from the past: Policy implications of historical fertility studies," Population and Development Review 5(2): 217-245.

Kohler, Hans-Peter. 2001. Fertility and Social Interaction: An Economic Perspective. Oxford: Oxford University Press.

Kohler, Hans-Peter, Jere R. Behrman, and Susan C. Watkins. 2001. "The density of social networks and fertility decisions: Evidence from South Nyanza District, Kenya," Demography 38(1): 43-58.

Manski, Charles F. 1993. " Identification of endogenous social effects: The reflection problem," Review of Economic Studies 60: 531-542.

Mason, Karen Oppenheim. 1997. "Explaining fertility transitions," Demography 34(4): 443-454.

Montgomery, Mark R. and John B. Casterline. 1993. "The diffusion of fertility control in Taiwan: Evidence from pooled cross-section, time-series models," Population Studies 47(3): 457-479.

_. 1996. "Social learning, social influence, and new models of fertility," Population and Development Review 22 (Supp.): 151-175.

— 1998. "Social networks and the diffusion of fertility control," Policy Research Division Working Paper No. 119. New York: Population Council.

Montgomery, Mark R. and Woojin Chung. 1999. "Social networks and the diffusion of fertility control in the Republic of Korea," pp. 179-209 in Richard Leete (ed.), Dynamics of Values in Fertility Change. Oxford: Oxford University Press. 
Montgomery, Mark R., Michele Gragnolati, Kathleen A. Burke, and Edmundo Paredes. 2000. "Measuring living standards with proxy variables," Demography 37(2): $155-174$.

Nag, Moni. 1984. "Some cultural factors affecting costs of fertility regulation," Population Bulletin no. 17. New York: United Nations.

Ngom, Pierre. 1995. "Resistance to family planning in Senegal: The role of women's informal conversations," paper presented at the Annual Meeting of the Population Association of America.

Palloni, Alberto. 2001. "Diffusion in sociological analysis," pp. 66-114 in John B. Casterline (ed.), Diffusion Processes and Fertility Transition: Selected Perspectives. Washington, DC: National Academy Press.

Rosero-Bixby, Luis and John B. Casterline. 1993. "Modelling diffusion effects in fertility transition," Population Studies 47(1): 147-167.

- 1994. "Interaction diffusion and fertility transition in Costa Rica," Social Forces 73(2): 435-462.

Rutenberg, Naomi and Susan Cotts Watkins. 1997. "The buzz outside the clinics: Conversations and contraception in Nyanza Province, Kenya," Studies in Family Planning 28(4): 290-307.

Valente, Thomas W. 1995. Network Models of the Diffusion of Innovations. Cresskill, NJ: Hampton Press.

Valente, T.W., S.C. Watkins, M.N. Jato, A. van der Straten, and L.P. Tsitsol. 1997. "Social network associations with contraceptive use among Cameroonian women in voluntary associations," Social Science and Medicine 45(5): 677-687.

Watkins, Susan Cotts. 1990. "From local to national communities: The transformation of demographic regimes in Western Europe, 1870-1960," Population and Development Review 16(2): 241-272.

Yinger, Nancy. 1998. Unmet Need for Family Planning: Reflecting Women's Perceptions. Washington, DC: International Center for Research on Women. 


\section{POLICY RESEARCH DIVISION WORKING PAPERS}

Recent Back Issues

1999

*120 John Bongaarts, "The fertility impact of changes in the timing of childbearing in the developing world."

*121 James F. Phillips, Wendy L. Greene, and Elizabeth F. Jackson, "Lessons from community-based distribution of family planning in Africa."

*122 Mark R. Montgomery, "Mortality decline and the demographic response: Toward a new agenda."

*123 Mark R. Montgomery, Mary ArendsKuenning, and Cem Mete, "The quantity-quality transition in Asia."

124 Barbara S. Mensch, Wesley H. Clark, Cynthia B. Lloyd, and Annabel S. Erulkar, "Premarital sex and school dropout in Kenya: Can schools make a difference?"

*125 John Bongaarts and Rodolfo A. Bulatao, "Completing the demographic transition."

126 Geoffrey McNicoll, "Population weights in the international order."
*127 Cynthia B. Lloyd, Carol E. Kaufman, and Paul Hewett, "The spread of primary schooling in sub-Saharan Africa: Implications for fertility change."

128 John B. Casterline, "The onset and pace of fertility transition: National patterns in the second half of the twentieth century."

*129 Mark R. Montgomery, Michele Gragnolati, Kathleen Burke, and Edmundo Paredes, "Measuring living standards with proxy variables."

130 Bamikale Feyisetan and John B. Casterline, "Fertility preferences and contraceptive change in developing countries."

*131 Martin Brockerhoff, "Urban growth in developing countries: A review of projections and predictions."

132 Omaima El-Gibaly, Barbara Ibrahim, Barbara S. Mensch, and Wesley H. Clark, "The decline of female circumcision in Egypt: Evidence and interpretation."

* No longer available 
133 Mary Arends-Kuenning and Sajeda Amin, "The effects of schooling incentive programs on household resource allocation in Bangladesh."

134 John Bongaarts and Charles F. Westoff, "The potential role of contraception in reducing abortion."

135 John B. Casterline and Steven W. Sinding, "Unmet need for family planning in developing countries and implications for population policy."

*136 Carol E. Kaufman, Thea de Wet, and Jonathan Stadler, "Adolescent pregnancy and parenthood in South Africa."

*137 Valerie L. Durrant and Zeba A. Sathar, "Greater investments in children through women's empowerment: A key to demographic change in Pakistan?"

138 Sajeda Amin, Alaka Malwade Basu, and Rob Stephenson, "Spatial variation in contraceptive use in Bangladesh: Looking beyond the borders."
139 Geoffrey McNicoll, "Managing population-environment systems: Problems of institutional design."

140 Barbara S. Mensch, Barbara L. Ibrahim, Susan M. Lee, and Omaima ElGibaly, "Socialization to gender roles and marriage among Egyptian adolescents."

141 John Bongaarts and Elof Johansson, "Future trends in contraception in the developing world: Prevalence and method mix."

142 Alaka Malwade Basu and Sajeda Amin, "Some preconditions for fertility decline in Bengal: History, language identity, and an openness to innovations."

143 Zeba Sathar, Cynthia B. Lloyd, Cem Mete, and Minhaj ul Haque, "Schooling opportunities for girls as a stimulus for fertility change in rural $\mathrm{Pa}-$ kistan."

* No longer available 
144 John Bongaarts, "Household size and composition in the developing world."

145 John B. Casterline, Zeba A. Sathar, and Minhaj ul Haque, "Obstacles to contraceptive use in Pakistan: A study in Punjab."

146 Zachary Zimmer, Albert I. Hermalin, and Hui-Sheng Lin, "Whose education counts? The impact of grown children's education on the physical functioning of their parents in Taiwan."

147 Philomena Nyarko, Brian Pence, and Cornelius Debpuur, "Immunization status and child survival in rural Ghana."

148 John Bongaarts and Zachary Zimmer, "Living arrangements of older adults in the developing world: An analysis of DHS household surveys."
149 Markos Ezra, "Ecological degradation, rural poverty, and migration in Ethiopia: A contextual analysis."

150 Cynthia B. Lloyd, Sahar El Tawila, Wesley H. Clark, and Barbara S. Mensch, "Determinants of educational attainment among adolescents in Egypt: Does school quality make a difference?"

151 Barbara S. Mensch, Paul C. Hewett, and Annabel Erulkar, " The reporting of sensitive behavior among adolescents: A methodological experiment in Kenya."

152 John Bongaarts, "The end of the fertility transition in the developed world."

153 Mark R. Montgomery, GebreEgziabher Kiros, Dominic Agyeman, John B. Casterline, Peter Aglobitse, and Paul C. Hewett, "Social networks and contraceptive dynamics in southern Ghana." 

